\title{
Panorama da nutrigenômica no Brasil sob a perspectiva da Bioética*
}

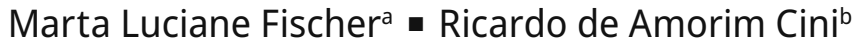 \\ - Amanda Amorim Zanattac - Norton Nohamad - Mauro Seigi Hashimoto

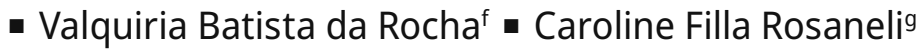

Resumo: a nutrigenômica tem configurado, no meio científico e popular, como alternativa para prevenir doenças, cuja predisposição determinada geneticamente pode ser evitada ou estimulada, dependendo do ambiente no qual o indivíduo se insere. Este estudo questionou o potencial da nutrigenômica em mitigar ou gerar vulnerabilidades. Objetivou-se traçar o panorama da nutrigenômica no Brasil sob a perspectiva da Bioética. O estudo consistiu em um mapeamento quantitativo do panorama da nutrigenômica no cenário científico e popular do Brasil, e em uma análise bibliográfica exploratória com o intuito de identificar os agentes e pacientes morais, bem como as vulnerabilidades com vistas a promover uma reflexão à luz da Bioética. O cenário da nutrigenômica no Brasil, elaborado a partir de 18 textos científicos e de 600 conteúdos populares, indicou a prematuridade da área no contexto científico em confronto com uma ampla incorporação pelo meio popular. A incorporação da Bioética na questão foi analisada em 44 artigos científicos, a partir dos quais foram identificados

* Artigo de pesquisa.

a Doutora em Zoologia. Docente do Programa de Pós-Graduação em Bioética, Escola Ciências da Vida, Pontifícia Universidade Católica do Paraná, Curitiba, Paraná, Brasil. E-mail: marta.fischer@pucpr.br ORCID -

b Doutorando em Poíticas Públicas. Mestre em Bioética. Tecnólogo em Gastronomia, Universidade Federal do Paraná, Curitiba, Paraná, Brasil. E-mail: riicardo.cini@hotmail.com ORCID o

c Mestra em Bioética. Licenciada em Ciências Biológicas, Programa de Pós-Graduação em Bioética, Escola Ciências da Vida, Pontifícia Universidade Católica do Paraná, Curitiba, Paraná, Brasil.

E-mail: amandaamorimzanatta@gmail.com ORCID •

d Mestre em Bioética. Filósofo, Programa de Pós-Graduação em Bioética, Pontifícia Universidade Católica do Paraná. Servidor público da Universidade Federal do Paraná, Curitiba, Paraná, Brasil.

E-mail: nohama@ufpr.br ORCID •

e Mestre em Bioética. Bacharel em Direito. Licenciado em Biologia, Programa de Pós-Graduação em Bioética, Escola Ciências da Vida, Pontifícia Universidade Católica do Paraná, Curitiba, Paraná, Brasil. E-mail: mauro.s.hashimoto@gmail.com ORCID o

f Mestre em Bioética. Teóloga, Programa de Pós-Graduação em Bioética, Pontifícia Universidade Católica do Paraná, Curitiba, Paraná, Brasil. E-mail: valquiria201161@hotmail.com

ORCID

g Doutora em Ciências da Saúde. Nutricionista. Docente do Programa de Pós-Graduação em Bioética, Escola Ciências da Vida, Pontifícia Universidade Católica do Paraná, Curitiba, Paraná, Brasil. E-mail: caroline.rosaneli@gmail.com ORCID 
como aspectos condicionantes de decisões do agente moral os contextos filosófico, biológico, cultural, legal e sanitário nos quais se insere. Foram elencadas as vulnerabilidades e mudanças de paradigmas necessárias para sua implementação no Brasil, a fim de diminuir o potencial de geração de vulnerabilidades. A Bioética pode e deve ter uma atuação mais ampla e efetiva nas questões da nutrigenômica ao normatizar, balizar e orientar o desenvolvimento dessa área promissora. Assim, deve visar às mudanças de paradigmas da ciência, dos profissionais, do mercado, do paciente e do consumidor para serem suprimidos os aspectos potenciais de geração das vulnerabilidades identificadas e contribuir para a qualidade de vida de todos os seres vivos desta e de futuras gerações.

Palavras-chave: bioética ambiental; ciências ômicas; nutrição; vulnerabilidade; saúde

Recibido: 19 de mayo de 2018 Aceptado: 30 de abril de 2020

Disponible en línea: 15 de septiembre de 2020

Cómo citar: Fischer ML, Rosaneli CF, Cini R de A, Zanata AA, Nohama N, Hashimoto MS, Rocha VB. Panorama da Nutrigenômica no Brasil sob a perspectiva da Bioética. Rev. latinoam. bioet [Internet]. 15 de septiembre de 2020; 20(1). Disponible en: https://doi.org/10.18359/rlbi.3475

\section{Panorama of nutrigenomics in Brazil from the perspective of Bioethics}

Summary: nutrigenomics has positioned itself, in the scientific and popular context, as an alternative to prevent diseases, which genetically determined predisposition can be avoided or encouraged, depending on the context the individual is at. The study investigated the potential of nutrigenomics in mitigating or generating vulnerabilities. The purpose was to establish the panorama of nutrigenomics in Brazil from the perspective of Bioethics. The study consisted of a quantitative mapping of the nutrigenomics panorama in the scientific and popular context of Brazil, and of an exploratory bibliographic analysis in order to identify moral agents and patients, as well as vulnerabilities to promote reflection in light of Bioethics. The scenario of nutrigenomics in Brazil, built from 18 scientific texts and 600 popular contents, evidenced the prematurity of the area in the scientific context in comparison with a wide incorporation by the popular media. The incorporation of Bioethics in the debate was analyzed in 44 scientific articles, from which the philosophical, biological, cultural, legal and health contexts in which it is found were identified as conditioning aspects of decisions of the moral agent. The vulnerabilities and paradigm changes necessary to implement it in Brazil were related, in order to mitigate the potential for generating vulnerabilities. Bioethics can and should have a broader and more effective action on nutrigenomics questionings by normalizing and guiding the development of this promising area. Thus, it must aim at paradigm shifts in science, professionals, the market, the patient and the consumer so that the potential aspects of generating the identified vulnerabilities are eliminated and contribute to the quality of life of all living beings in the world of this and future generations.

Keywords: environmental bioethics; ohmic sciences; nutrition; vulnerability; health 


\section{Panorama de la nutrigenómica en Brasil desde la perspectiva de la Bioética}

Resumen: la nutrigenómica ha configurado, en el medio científico y popular, como alternativa para prevenir enfermedades, cuya predisposición determinada genéticamente puede evitarse o estimularse, dependiendo del entorno en el que el individuo se encuentra. El estudio indagó el potencial de la nutrigenómica en mitigar o generar vulnerabilidades. El propósito fue establecer el panorama de la nutrigenómica en Brasil desde la perspectiva de la Bioética. El estudio ha consistido en un mapeo cuantitativo del panorama de la nutrigenómica en el contexto científico y popular de Brasil, y en un análisis bibliográfico exploratorio con el fin de identificar los agentes y pacientes morales, así como las vulnerabilidades para promover una reflexión a la luz de la Bioética. El escenario de la nutrigenómica en Brasil, elaborado desde 18 textos científicos y 600 contenidos populares, evidenció la prematuridad del área en el contexto científico en confronto con una amplia incorporación por el medio popular. La incorporación de la Bioética en el debate se analizó en 44 artículos científicos, a partir de los que se identificaron como aspectos condicionantes de decisiones del agente moral los contextos filosófico, biológico, cultural, legal y sanitario en los que se encuentra. Se relacionaron las vulnerabilidades y cambios de paradigmas necesarios para implementarlo en Brasil, con la finalidad de mitigar el potencial de generación de vulnerabilidades. La Bioética puede y debe tener una actuación más amplia y efectiva en los cuestionamientos de la nutrigenómica al normalizar y orientar el desarrollo de esta área prometedora. Así, debe apuntar a los cambios de paradigmas da ciencia, de los profesionales, del mercado, del paciente y del consumidor para que se supriman los aspectos potenciales de generación de las vulnerabilidades identificadas y aportar para la calidad de vida de todos los seres vivos de esta y de futuras generaciones.

Palabras clave: bioética ambiental; ciencias ohmicas; nutrición; vulnerabilidad; salud 


\section{Introdução}

A Bioética inseriu uma nova perspectiva no diálogo com a saúde global ao subsidiar a resolução de conflitos entre o desenvolvimento tecnológico e os impactos ambientais plausíveis de afetarem local ou globalmente a saúde das pessoas, dos animais e do ambiente, em uma amplitude física, mental e social $(1,2)$.

A interdependência entre a saúde e o ambiente já se fazia presente nas pautas da saúde pública no final do século passado no Brasil (3), assim como no conceito de "determinantes sociais da saúde", em que condutas individuais e coletivas foram consideradas dependentes das condições políticas, econômicas, sociais, culturais e ambientais existentes no país (4). Por meio de diferentes instrumentos de diagnósticos, monitoramento e intervenções, inseridos em políticas de Vigilância Ambiental e Atenção Primária Ambiental (apa) (5-7), que almejam atingir a sustentabilidade e equidade social mediante a identificação e mitigação dos impactos decorrentes da urbanização e da industrialização $(4,8)$ - bem como do surgimento e ressurgimento de agravos à saúde, epidemias e pandemias, perdas materiais, devido a catástrofes, e descaracterização dos habitats naturais (9) - , será possível definir como as sociedades têm se organizado para solucionar seus problemas de saúde global (10).

A atuação da Bioética em questões ambientais que aspiram à sobrevivência do planeta já havia sido proposta no início da década de 1970 por Potter (11). O oncologista estadunidense precursor da Bioética pontuava a óbvia, direta e inquestionável relação entre a saúde humana, animal e ambiental. Contudo, a hegemonia do sistema capitalista, a insustentável exploração dos recursos naturais, a inserção drástica das tecnologias no sistema industrial e na vida pessoal conduziram a alterações do modo de vida, colocando em risco o suprimento das necessidades biológicas moldadas por milhares de anos de evolução (2).

A nutrigenômica tem configurado, no meio científico e popular, como alternativa para prevenir doenças, cuja predisposição genética pode ser suprimida ou estimulada, dependendo do ambiente e dos nutrientes incorporados (12). Segundo Fujii, Medeiros e Yamada (13) e Subbiah (14), novas áreas denominadas de "nutrigenômica" e "nutrigenética" são derivadas do Projeto Genoma, o qual permitiu a documentação de polimorfismos associados ao metabolismo, o que evidencia a interação genes-nutrientes-bioativos e a atuação destes na modulação da expressão gênica, bem como o efeito da variação genética na interação dieta-doença. Os autores alertaram para o desafio da compreensão entre essa interação e a expectativa de proporcionar ao paciente uma intervenção nutricional personalizada, que revolucionaria os cuidados de saúde pública, os cuidados em saúde, além do mercado de alimentos (15). Ouhtit (16) circunscreveu a nutrigenômica à interpretação das respostas celulares a determinados nutrientes e seu impacto na homeostase e expressão gênica, proteica e metabólica, acessada por diferentes técnicas, tais como: proteômica (geração de proteínas), metabolômica (nível de metabólitos e suas modificações temporais), transcriptoma (interações complexas entre fatores genéticos e ambientais) e ciências ômicas (determinação de biomarcadores e diagnóstico precoce); além disso, constitui a produção de nutracêuticos como um ponto de confluência com farmacogenômica (12). Outras vertentes, como apresentou $\mathrm{Ou}-$ htit (16), pontuam a associação entre as pesquisas emergentes da nutrigenômica e a medicina complementar e alternativa, atrelando respostas antidoenças a técnicas como: uso de ervas (ayurveda), acupuntura, yoga, meditação e suplementos.

Embora a nutrigenômica traga atrelada a si uma abordagem reducionista e aparentemente de fácil operacionalização, que transmite a mensagem de que basta consumir os nutrientes adequados em doses corretas para promover a homeostase, essa área tem levantado inúmeros questionamentos de ordem ética. Nesse contexto, deve-se considerar que a vida artificial das sociedades modernas e a exposição a produtos alimentícios industrializados têm impactado negativamente o organismo, aumentando a vulnerabilidade às doenças $(11,17)$. Além disso, a apropriação dos princípios da nutrigenômica pelo mercado capitalista e a possibilidade de ser utilizada para interesses escusos conclamam 
a reflexão dos prós e contras sob a perspectiva da Bioética. Isso se faz importante, uma vez que esta busca formas de intervenção na mitigação dos conflitos por meio do levantamento dos argumentos dos atores envolvidos na questão, além da identificação das vulnerabilidades.

O presente estudo se justifica perante a configuração da nutrigenômica no meio médico como alternativa de medicina integrativa e personalizada, que visa à avaliação individual por meio do diagnóstico e propõe intervenções com suplementação. Contudo, além de não ser reconhecida pelo Conselho Profissional de Medicina no Brasil, que alega serem os conhecimentos ainda incipientes para validar uma nova área de atuação, tem sido cautelosamente abordada por outras áreas como a própria Nutrição $(18,19)$, a qual, embora aponte perspectivas, também considera que ainda se conhece pouco sobre o tema.

Concomitantemente, tratamentos dispendiosos prometem saúde e juventude, angariando pessoas vulneráveis diante de um sistema de saúde que as uniformiza ao não atender suas necessidades individuais. Essas pessoas, muitas vezes destituídas de perspectiva de cura para suas enfermidades, submetem-se à elevada alocação monetária e em expectativa. Uma rápida busca pelas redes sociais elenca inúmeros vídeos de divulgação científica como a suplementação da vitamina d, b12 e Ômega 3 , com a promessa de resolver questões que perpassam a recuperação de memória, o ganho de massa muscular, até a prevenção e cura do autismo, da degeneração muscular, do acidente vascular cerebral (conhecido pela sigla avc) e dos problemas cardíacos e imunológicos. Considerando o pressuposto de que cada ser humano é geneticamente único e fenotipicamente distinto (12) e diante do alerta da disseminação multidisciplinar do termo no meio científico e popular $(20,21)$, conclama-se a avaliação ética, legal e social. Assim, é importante que a questão seja avaliada sob a perspectiva da Bioética e que sejam elencados os atores (agentes e pacientes morais) envolvidos, seus argumentos e vulnerabilidades.

O presente estudo se justifica perante a configuração da nutrigenômica no meio médico como alternativa de medicina integrativa e personalizada, que visa à avaliação individual por meio do diagnóstico e propõe intervenções com suplementação.. Assim, objetivou-se traçar o panorama na nutrigenômica no Brasil sob a perspectiva da Bioética. O estudo se constitui de uma abordagem multidisciplinar que abarca: Biologia, Nutrição, Direito, Filosofia e Comunicação. A investigação tem como foco as informações disponíveis para o cidadão contemporâneo, principalmente de grandes centros urbanos, vulnerável a um ambiente artificializado que perpetua o paradigma do imediato, prático e descartável, com a consolidação do uso de produtos alimentícios industrializados. Estes, somados às alterações e poluições ambientais, ao estresse emocional e ao esgotamento físico, têm conduzido à perda de saúde e da qualidade de vida. Nesta investigação, levanta-se a hipótese de que o indivíduo já vulnerável tenha essa condição potencializada, caso não se identifiquem e interrompam processos deletérios. Além disso, pode ser alvo de vulnerabilidades provocadas pelo comércio e por interesses que comprometam sua autonomia. Os dados teóricos e quantitativos foram analisados sob a perspectiva da Bioética, com a relação das vulnerabilidades associadas com a pesquisa e prática da nutrigenômica. Esta análise foi balizada pela ideia central de que as inserções de tecnologia na mitigação de problemas decorrentes do desenvolvimento tecnológico podem potencializar as vulnerabilidades. Isso porque o papel de agente e paciente moral se alterna em uma complexa rede de interesses pessoais, econômicos e científicos, o que demanda a interferência de ferramentas de intermediação de conflitos orientadas para mudanças de paradigmas que visam a soluções consensuais e justas.

\section{Método}

O presente estudo consistiu em um mapeamento quantitativo do panorama da nutrigenômica no cenário científico e popular do Brasil, e em uma análise bibliográfica exploratória com o intuito de identificar os agentes e pacientes morais, bem como as vulnerabilidades com vistas a promover uma reflexão à luz da Bioética. 
A contextualização acadêmica nacional se deu por meio do levantamento de textos científicos produzidos por pesquisadores brasileiros a respeito da nutrigenômica, a fim de caracterizar o panorama e os conflitos apontados por essas pesquisas. Os textos foram recuperados pelo Portal Regional da Biblioteca Virtual de Saúde em maio de 2017, com a utilização dos descritores "nutrigenômica" e "nutrigenomics", condicionados ao termo "Brasil", para um total de 30 textos, dos quais permaneceram 18 após a exclusão dos duplicados. Concomitantemente, foram registradas todas as referências vinculadas apenas ao termo "nutrigenomics", sem a exclusão de nenhuma delas. Os textos foram categorizados conforme assunto e ano, e avaliados os conflitos identificados pelos autores.

A abordagem popular foi caracterizada por meio da avaliação exploratória do conteúdo veiculado na mídia digital por meio da utilização, devido à popularidade, do motor de busca google. com destituído do login. O conteúdo foi recuperado com a aplicação dos termos ou expressões: a) "nutrigenômica" (12/6/2017, 45.400 resultados), b) "testes de nutrigenômica" (22/5/2017, 263 resultados), c) "nutrigenômica animal" (2/7/2017, 17.500 resultados). Todos em português, com a intenção de restringir a amostra ao recorte de abrangência nacional. Para todos os resultados, foram incluídos na amostra os 100 primeiros registros, os quais foram transpostos para planilhas eletrônicas e categorizados conforme a técnica semântica da análise de conteúdo de Bardin (22). Além dos conteúdos digitais veiculados em sites, blogs e portais, foi mapeada a aplicação do termo igualmente nas redes sociais Facebook e YouTube. Para esta última, além do termo "nutrigênomica" (2/7/2017, 3.370 resultados), foi acrescida a categorização dos 100 primeiros registros veiculados ao termo "nutrigenética" (2/7/2017, 2.380 resultados) e de 100 registros referentes à expressão "medicina integrativa" (2/7/2017, 24.700 resultados), devido à intersecção entre essas áreas. Os conteúdos foram categorizados conforme a origem, o público e a informação passada. A fim de mapear a abrangência do mesmo termo na rede social Facebook, foi registrado também o número de participantes e inscritos.
A inserção da nutrigenômica nos debates bioéticos se deu pelo levantamento das questões éticas abordadas em textos científicos recuperados pelo Portal da Capes (Coordenação de Aperfeiçoamento de Pessoal de Nível Superior) no dia 28 de junho de 2017 com a utilização do unitermo "nutrigenomics", condicionado ao termo "bioethics". Dos 134 textos recuperados, após a exclusão dos conteúdos repetidos e daqueles que não traziam o recorte pretendido, restaram 44 que elencavam as questões éticas e 11 que traziam alguma referência à Bioética.

A homogeneidade da amostra resultante da categorização foi acessada por meio da aplicação do teste não paramétrico do qui-quadrado, tendo como hipótese nula a homogeneidade das frequências reativas a cada variável ao nível de significância de $95 \%$.

\section{Resultados}

\section{Nutrigenômica no cenário brasileiro sob a perspectiva científica}

Metade da produção científica associada à nutrigenômica condicionada ao Brasil, que teve seu auge em 2014, abordou as temáticas: suplementação, dietas ou ingestão de determinados nutrientes para mitigar efeitos de doenças ou suas modificações no dna. Registraram-se também as associações de doenças com genes presentes no dna $(33,3 \%)$ e estudos de revisão sobre os aspectos da nutrição e/ou nutrigenômica (17\%). Já o descritor "nutrigenomics" em abrangência global resultou em 939 registros relativos ao período de 2001 a 2017 , com prevalência em 2007 , destacando-se como temas abordados: nutrigenômica (39,2\%), fenômenos fisiológicos da nutrição (14,9\%) e dieta $(13,6 \%)$ (Figura 1).

A análise do conteúdo dos artigos nacionais indicou potenciais conflitos. SantanaSantos, Prosdocimi e Ortega (23) apenas citaram que a nutrigenômica pode trazer complicações, dependendo de como os testes são disponibilizados à sociedade. Os aspectos econômicos referentes à utilização dessa nova ferramenta também 
foram considerados (24), principalmente quanto à dificuldade de acesso. Veem-se também questões sobre os possíveis problemas e incertezas à saúde provenientes do consumo de alimento enriquecido (suplementação), seja pela falta de estudos, seja pelas controversas (25). Fujii, Medeiros e Yamada (13) destacam a correlação da Bioética com a nutrigenômica, uma vez que esta ainda precisa de muitas pesquisas, tendo em vista suas incertezas, cuja realização é orientada pela Bioética. A proteção das informações dos indivíduos foi levantada por Sales, Pelegrini e Goersch (26), ao afirmarem que é necessária a existência de órgão de proteção contra as empresas que possam oferecer o serviço. Os outros artigos não levantaram quaisquer pontos de conflitos decorrentes da utilização da nutrigenômica.

\section{Nutrigenômica no cenário brasileiro sob a perspectiva popular}

O conteúdo textual disponível na mídia digital indicou um posicionamento direcionado para clientes, para a população geral e para a academia que aborda principalmente o conteúdo sobre a fundamentação da nutrigenômica, com conceitos, definição, processos e aplicação na área da saúde, na prevenção e tratamento de doenças (Figura 1).

$\mathrm{Na}$ rede social YouTube, têm sido divulgados vídeos com explanação e palestras, cujo conteúdo se refere, na sua maioria, à fundamentação teórica com exposição de conceitos, definições e processos, sendo este mais evidente para o termo "nutrigenômica", assim como à apresentação das possibilidades de aplicação no dia a dia, sendo evidenciada uma relação da nutrigenética com a obesidade (c2(3)=12,7; $\mathrm{P}<0,001)$ e da medicina integrativa como uma alternativa à medicina tradicional (c2(3) $=38,7 ; \mathrm{P}<0,001)$ (Figura 1).

No Brasil, a rede social Facebook dispõe de 102 grupos de discussão e 86 páginas sobre o tema até o período de análise. Os primeiros foram caracterizados principalmente por iniciativas pessoais que congregavam pequeno número de participantes, cujo objetivo principal é divulgar notícias sobre a temática, com relação também a grupos escolares e profissionais. Já as páginas que congregaram grande número de seguidores apresentaram cunho predominantemente comercial (Figura 1).

O conteúdo vinculado aos testes de nutrigenômica referiu-se ao oferecimento de testes e à discussão sobre o tema. A maioria dos sites de testes (40\%) não disponibiliza informações precisas quanto aos procedimentos de coleta de material, ao diagnóstico e ao retorno, e não responderam prontamente à solicitação de informações por e-mail. Além disso, 33,3\% indicam a necessidade de consulta prévia com médicos, nutricionistas ou laboratórios e apenas 13,3\% dão autonomia para o cliente coletar o material por meio de kit, enviar pelo correio e obter o resultado por meio digital, muitas vezes ligados ao laboratório italiano. $\mathrm{O}$ custo médio dos testes foi de $2.585,00$ reais, com até 40 dias para o resultado (Figura 1).

$\mathrm{Na}$ avaliação do mapeamento do conteúdo associado à expressão "nutrigenômica animal", $44 \%$ não apresentavam associação com a temática ou consistiam em réplicas de notícias já caracterizadas. Das notícias analisadas (56\%), observou-se que a maioria (79\%) detinha como eixo orientador animais de produção, com o elenco de fatores como a intensificação da produtividade, a qualidade da carne, a produção de alimentos funcionais e com melhores processos metabólicos, bem como as técnicas de produção sustentável. Com índices menores (5\%), foram encontrados registros relacionados a estudos nutrigenômicos que envolviam animais de pesquisa, com a identificação de fatores genéticos como possíveis causas para melhorias e transtornos metabólicos em humanos e animais. Apenas $16 \%$ das notícias analisadas continham informações relacionadas a animais domésticos, com a abordagem de temáticas relacionadas ao manejo nutricional, ao aumento da longevidade, bem como à relação de enfermidade que acometem humanos e animais (Figura 1). 


\section{Nutrigenômica no cenário brasaileiro}

\section{Contexto científico}

39\%: nutrigenômica

15\%: fisiologia

14\%: dieta

$11,7 \%$ : doenças

8\%: genômica

7\%: polimorfismo

$3,2 \%$ : estado nutricional
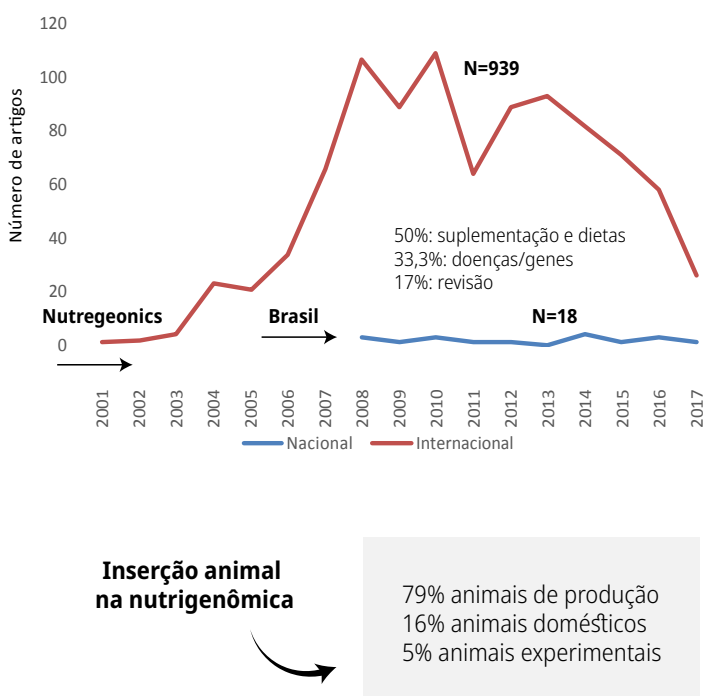

\section{Contexto popular}

\begin{tabular}{|c|}
\hline Conteúdo digital \\
\hline $\begin{array}{l}34,5 \% \text { : clientes } \\
28,2 \% \text { : público geral } \\
24,5 \% \text { : academia } \\
\text { 12\%: profissionais }\end{array}$ \\
\hline
\end{tabular}

Redes sociais

Facebook

102 grupos fechados:

$38,3 \pm 143(99 ; 1-1.151)$ participantes

86 páginas (87\% marketing):

$1.502 \pm 6630(83 ; 1-57.929)$ seguidores

46\%: fundamentação, conceitos, definição e processos

31\%: aplicação na saúde

9\%: comercial

4\%: nutrição personalizada

$3 \%$ : eventos

YouTube

32\%: explanação

29\%: palestras

23\%: entrevistas

$10,4 \%$ marketing

5\%: acadêmico
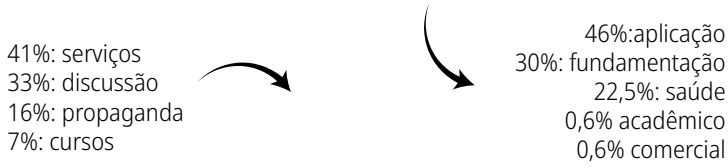

$$
\begin{array}{r}
13,3 \% \text { pela } \\
\text { internet - } \\
\mathrm{R} \$ 2.585 \pm 933 \\
(14 ; 790-4500)- \\
\text { até } 40 \text { dias }
\end{array}
$$

Nutrigenômica: 52\% fundamentação Nutrigenética: $61,5 \%$ aplicação obesidade

Medicina integrativa: 56\% aplicação alternativa para medicina tradicional

Figura 1. Fluxograma dos resultados obtidos com a categorização da abordagem científica e popular da nutrigenômica no cenário brasileiro.

*A homogeneidade da amostra das categorias foi testada pelo teste do qui-quadrado. Os valores significativamente maiores $(P<0,05)$ estão destacados em negrito e letra de maior tamanho.

Fonte: elaboração própria.

\section{Análise da nutrigenômica sob a perspectiva da interface entre Bioética e saúde global}

A expectativa de atuação da nutrigenômica foi ressaltada em 47 referências agrupadas em oito categorias, relacionadas principalmente à prevenção das doenças, à aplicação na saúde pública e à importância do conhecimento gerado $(\mathrm{c} 2(7)=47,2$; $\mathrm{P}<0,001)$. Por sua vez, foram registrados 165 pontos conflitantes agrupados em 24 categorias; dos registros relativos a mais de cinco citações (58\%), a maioria indicou a incipiência de diretrizes para os diagnósticos. Logo, demandam uma regulamentação mais incisiva que questione a idoneidade das informações passadas tanto pelo participante das pesquisas quanto pelo paciente e pelo cidadão (c2(11) $=19,2 ; \mathrm{P}<0,001)$. Os textos recuperados evidenciaram que a Bioética tem sido pouco inserida nos debates sobre a nutrigenômica, nos quais apenas 11 traziam alguma referência da Bioética associada à atuação dos comitês de ética na proteção dos participantes da pesquisa, dos vulneráveis, dos interesses da sociedade, além de regulamentar, orientar e acompanhar pesquisas e aplicação dos testes (Figura 2). 


\section{Nutrigenômica na perspectiva bioética}

\section{Benefícios}

Prevenção de
doenças 42,5\%

Saúde pública: 17\% Conhecimento interação 14,9\% Segurança alimentar: 10,6\% Aplicação no esporte: $6,4 \%$ Biofortificação: 4,2\% Personalização: 2,1\% Indústria de alimentos: 2,1\%

\author{
Bioética \\ Proteger participantes de \\ pesquisas, interesses da \\ sociedade e vulneráveis. \\ * Regulamentar, orientar e \\ acompanhar pesquisas e \\ testes. \\ *Intermediar decisões \\ conflitantes.
}

\author{
Vulnerabilidades \\ Comunicação: 11,5\% \\ Diagnóstico: $11 \%$ \\ Capacitação: 9,7\% \\ Informações genéticas: 9\% \\ Discriminação: $8,5 \%$ \\ Consumidor: $8 \%$ \\ Transformar alimento em \\ medicamento ou perigo: $6,2 \%$ \\ Biobancos: 5,4\% \\ Comprovação científica: 5,4\% \\ Organismos geneticamente \\ modificados: $4,3 \%$ \\ Perda de autonomia: $3,6 \%$
}

Equidade: $3,6 \%$

Figura 2. Fluxograma dos resultados obtidos com a revisão sistemática de textos científicos sobre a nutrigenômica sob a perspectiva bioética com a identificação de benefícios, vulnerabilidades e papel da Bioética

Fonte: elaboração própria.

\section{Discussão}

Os resultados obtidos no presente estudo trazem um panorama da nutrigenômica no Brasil que evidencia a necessidade do estabelecimento de uma base ética sólida, a fim de minimizar os riscos de geração de vulnerabilidades já identificadas em outros países.

\section{Nutrigenômica no cenário brasileiro sob a perspectiva científica}

Os resultados obtidos na caracterização científica indicaram a prematuridade da nutrigenômica no Brasil e evidenciaram o tardio envolvimento dos pesquisadores (a partir de 2008), quando comparado com o início das veiculações globais iniciadas em 2001. Consequentemente, os termos dos textos brasileiros igualmente demonstram restrição temática à aplicação. Ao contrário dos resultados do presente estudo, Bubela e Taylor (27) realizaram um mapeamento no Canadá e verificaram um aumento considerável de artigos científicos veiculados em revistas de alta qualidade que se referiram à nutrigenômica. Contudo, ressaltaram que, em contraposição às promessas de aplicação futura, os estudos de testes clínicos foram poucos; destes, menos de $20 \%$ são associados a humanos, e a maioria relativa a estudos de cultivo celulares ou roedores. O baixo interesse científico brasileiro na discussão da temática pode aumentar a vulnerabilidade da população, a qual já tem à disposição conteúdos disseminados pelo meio digital, sem a devida preocupação de como intermediar a comunicação entre a sociedade e os profissionais para a compreensão e aplicação dessa nova tecnologia em prol da saúde.

\section{Nutrigenômica no cenário brasileiro sob a perspectiva popular}

A caracterização popular indicou igualmente a inserção da temática com o predomínio de conteúdos sobre a fundamentação da área. No entanto, a veiculação desse conteúdo esteve atrelada a instituições comerciais ou inciativas pessoais, o que pode potencializar as vulnerabilidades.

O cidadão tem direito de informação para que possa tomar suas decisões com consciência (17). Contudo, muitos dados são omitidos do consumidor, a exemplo do processo de produção, da armazenagem e consumo dos alimentos. A educação 
promovida também instrui o cidadão a delegar deliberadamente a responsabilidade para outras instâncias, o que o faz sentir confiante na sua idoneidade. A mídia se apropria de alguns dados e gera marketing que é incorporado por distintos segmentos que promovem a disseminação da importância de hábitos de vida saudáveis. Muitas vezes, a incorporação de alternativas e posicionamentos conflitantes, apoiados ou não em dados científicos, torna complexo o que deveria ser mais simples, a um ponto de o consumidor rejeitar as orientações. Bubela e Taylor (27) realizaram um estudo similar no Canadá em diferentes mídias e constataram que as descobertas das áreas, principalmente vinculadas a pesquisas científicas testadas em animais, eram entusiástica e exageradamente associadas aos benefícios para a saúde humana, sendo os riscos e limitações raramente explorados. Neste estudo, um terço estava relacionado com empresas, a partir da exploração de testemunhos principalmente ligados a celebridades e com foco em serviços e produtos.

A partir da constatação de que o consumidor pode se saturar de dados conflitantes, Sutton (28) apresentou dados que informam que a atribuição de benefícios para os alimentos funcionais pela população caiu de $71 \%$ para $46 \%$, alegando confusão por causa da quantidade de resultados de pesquisas divergentes. Inclusive, o autor salientou que $70 \%$ preferiram a expressão "dieta personalizada" ao invés da "nutrigenômica", o que reafirma o uso de informação genética para a dieta. Segundo Korthals e Komduur (29), não é possível determinar uma nova forma de conduta com estilos de vida e dietas permeadas mais por incertezas do que por comprovações. As dúvidas entre pesquisas, indicações e orientações díspares leva a sociedade a não identificar a conexão entre agentes, ações, seus efeitos e intenções e a reajustar suas opiniões de acordo com os interesses ou opiniões do momento. Consequentemente, o equilíbrio entre certezas e incertezas será balizado pela relação indivíduo-contexto, o que aumenta a vulnerabilidade do cidadão.

Os testes não pareceram estar tão disseminados no Brasil como registrado em contexto mundial. O conteúdo condicionado ao termo ainda versa sobre debates ou cursos, e a maioria dos testes condicionou a consulta prévia e o contato feito via laboratório. Castle e Reis (20) verificaram que milhares de testes já foram realizados no âmbito mundial, os quais são facilmente adquiridos pela internet, cujo paciente coleta e envia seu material genético e informações pessoais, e recebe um laudo da identificação de polimorfismos relacionados com o metabolismo. A consequente recomendação dietética, de suplementos e de produtos próprios ocorre à margem da regulamentação, potencialmente sem um profissional que faça a intermediação. Os autores apresentaram alguns experimentos nos quais amostras com dados fictícios foram enviadas para empresas diversas. Os resultados demonstraram orientações iguais para casos díspares, desconsideração de dados biológicos e culturais, e previsões não comprovadas ou ambíguas. Isso ilustra um conflito ético importante que, ao ser identificado, deve ser mitigado.

\section{Nutrigenômica sob a perspectiva animal}

Embora o mapeamento da aplicação nutrigenômica em animais tenha evidenciado direcionamento para os animais de produção, há expectativa de aplicação na melhoria da saúde dos animais de companhia. A convivência com humanos tem desencadeado doenças similares nos animais, relacionadas principalmente a alterações nos estilos de vida e de alimentação. O consumo excessivo de carboidratos, a castração, o sedentarismo e a diminuição de resistência à insulina suscetibilizam os animais a enfermidades crônicas, tais como obesidade, diabete e desordens renais $(30,31)$. Mendes-Jr, Passos, Gáleas, Secchin e Aptekmann (32) desvincularam a obesidade, que atinge cerca de $25 \%$ dos gatos e $40 \%$ dos cães $(30,33)$, da relação restrita à raça ou à idade, vinculando-a principalmente com hábitos alimentares, diminuição de atividade e livre acesso ao alimento $(30,34)$. Acresce-se a estes, o aumento da expectativa de vida dos animais, o que acarreta o pronunciamento de manifestações de doenças degenerativas das articulações como artrite e artrose, deficiências renais, hipertireoidismo, doenças cardíacas e hipertensão arterial (35-37). Cerca

M. L. Fischer - R. de Amorim Cini - A. Amorim Zanatta - N. Nohama 
de 15\% dos animais de companhia estão desenvolvendo hipersensibilidade alimentar manifestada em alterações dérmicas (38), registradas sobretudo em cães, provavelmente relacionada à elevada diversidade de raças. Devido aos sintomas alergênicos se manifestarem ao nível cutâneo, os tutores não estabelecem relação com a alimentação (39, 40), a qual pode estar associada aos ingredientes utilizados nas rações comerciais e aos métodos de processamento (41).

O desenvolvimento de produtos alimentícios para os animais de companhia também tem passado por mudanças e é subsidiado pela tendência das pessoas em antropomorfizar os animais e em investir em aquisições que promovam o bem-estar e a saúde destes (42). Pesquisas recentes elucidam que o estado nutricional, a gestação e o pós-nascimento dos animais influenciam diretamente no metabolismo ao longo da vida, inclusive no risco de contração de doenças (42). Segundo Camilo, Sakamoto e Gomes (43), é eficaz a medida mitigatória de prover uma alimentação que considere a necessidade e o consumo energético, condicionada a fatores como idade, raça e tamanho. Contudo, contrariamente ao desenvolvimento da nutrigenômica aplicada na criação de animais de corte e criação $(44,45)$ e à parte das possibilidades oferecidas pelo mercado, ainda são necessárias pesquisas sobre os nutrientes essenciais, suas funções, doses e influência na promoção de saúde ao longo da vida do animal.

\section{Análise da nutrigenômica sob a perspectiva da interface entre Bioética e saúde global}

A abordagem da nutrigenômica sobre o viés ético aponta benefícios atrelados principalmente às medidas preventivas de doenças e altamente favoráveis para mitigar vulnerabilidades relacionadas com a vida nas sociedades modernas; contudo, apresenta um elevado potencial de geração de vulnerabilidades contrário ao que destaca a proteção dos vulneráveis na Declaração Universal sobre Bioética e Direitos Humanos (46). Nesse sentido, são apresentados os aspectos condicionantes de decisões do agente moral, que devem ser considerados em uma reflexão sob a perspectiva da Bioética, tais como o contexto filosófico, biológico, cultural e legal da alimentação, com a relação das vulnerabilidades associadas à nutrigenômica e os apontamentos das mudanças de paradigmas necessárias para sua implementação no Brasil, com vistas à diminuição do potencial de geração de vulnerabilidades e à prevenção de mudanças de paradigmas da ciência, dos profissionais, do mercado econômico, do consumidor e do paciente.

\section{Inserção da nutrigenômica nos contextos filosófico, biológico e cultural}

O processo civilizatório ocidental, como resultado da relação do homem com a natureza e baseado no conhecimento científico - o qual considera o pensamento decorrente da Antiguidade grega (Platão e Aristóteles), da época Medieval (São Tomás de Aquino), dos tempos modernos (em especial, os séculos xvi e xvii, representados por pensadores como Nicolau Copérnico, Thomas Hobbes, René Descartes, Isaac Newton, Immanuel Kant, e o século XIX, com Hegel, Darwin, Spencer) e da visão contemporânea (Hans Jonas, Arthur Koestler, Lutzenberger e Kesselring) - evidencia a consolidação do pronunciamento do domínio do homem sobre a natureza e da sua exploração pela técnica, na qual não se percebe como parte integrante, o que o torna simultaneamente ator e vítima do seu próprio progresso. Essa análise filosófica da questão mostra que a construção do homem moderno passou por uma sequência atrelada ao processo evolutivo do conhecimento, que o conduziu ao exercício de múltiplos papéis na relação com a natureza, ora se posicionando como parte, ora como expectador e, ainda, como dominador.

A ciência, diante da impossibilidade de retornar ao estágio prévio à degradação e à insalubridade atual, passou a ser direcionada na busca de meios de adaptar o homem, como os demais seres vivos de interesse comercial ou social, a esse ambiente artificialmente inóspito à vida no planeta. A evolução do pensamento humano e a forma como se percebia conduziram ao cenário atual, cuja relação insustentável e predatória da natureza evidencia inegáveis e catastróficas consequências, 
potencialmente irreversíveis (11). O questionamento é se o atalho que o ser humano acreditava que o levaria a uma vida mais leve, sem tanto esforço físico, que o liberaria para dispor de mais tempo para viver, o prendeu em uma teia de artificialidade que frustrou a expectativa de retomar o ponto inicial. Partindo do pressuposto da impossibilidade de retornar a uma relação natural com o ambiente a partir de uma reversão dos danos já causados à natureza, a outra opção seria, por meio do conhecimento dos processos e da tecnologia, promover a adaptação do homem ao ambiente alterado, mediante a manipulação genética e epigenética, constituindo como nova meta o domínio do caos (47).

O conflito entre o corpo biológico do ser humano paleolítico, de mais de 200 mil anos, lentamente moldado pela evolução, e as demandas de adaptação decorrentes das intensas e exponenciais mudanças tecnológicas do homem neolítico é um ponto relevante para os estudos genéticos e principalmente os nutrigenômicos (48). Considerando que, em menos de $4 \%$ da sua história de vida, o Homo sapiens sapiens foi exposto a essas novidades, não é plausível de esperar uma adaptação instantânea. Os alimentos gerados pelos novos meios de produção neolítico criaram tensão ao entrarem em contato com o genoma lentamente selecionado para a interação com os alimentos disponíveis no ambiente natural, subjugados às disponibilidades sazonais e aos inerentes contaminantes biológicos de uma época sem saneamento. Os novos alimentos caracterizam-se por carências de determinados nutrientes, abundância de calorias, diversidade de elementos artificiais e contaminantes de agrotóxicos. Para Zwart (48), o conflito entre as dietas neolíticas e os genomas paleolíticos incorreu nos problemas que hoje a saúde pública investe para remediar, tais como obesidade, diabetes, doenças cardiovasculares, câncer de colón e intolerâncias alimentares. $\mathrm{O}$ autor sugere a interação entre pesquisadores da genômica e da arqueologia a fim de que se insiram na sociedade dietas transneolíticas compostas por alimentos paleolíticos, que readaptem a interação ambiental com genomas acrescidos de mudanças de modos de vida.
Comer é um ato de convívio social, de identidade, com costumes que simbolizam um povo ou uma crença, sendo o alimento concebido pelo viés saúde, seja pelo comportamento por meio de restrições, seja por sua abundância de variedade e quantidade (49). Boff (50) utilizou o termo "comensalidade" para representar o ato de comer como um convívio social; segundo o autor, esse comportamento permitiu o salto da animalidade em direção à humanidade; nesse sentido, a destituição dessa condição é um meio de retornar à desumanidade e à crueldade, tal como já se apresenta em muitas situações atuais. Nas sociedades contemporâneas, o consumo alimentar tem refletido influências da mídia nas escolhas, o que retira do alimento seu papel central como cultura, resultando no vício em açúcar, sal e gordura. Dessa forma, o valor atribuído ao alimento passa a ser o prazer imediato e a saciedade dos vícios, incorrendo em uma diversidade de agravos à saúde $(49,51)$.

A ciência da nutrição é a área base da nutrigenômica e são justamente os seus fundamentos que devem ser usados para permear a orientação do homem na busca da sua restauração natural aos seus processos hemostáticos. Fujii, Medeiros e Yamada (13) classificaram a nutrigenômica como o que há de mais atual na ciência da nutrição, indicando a disseminação no meio acadêmico e profissional; contudo, assumiram a necessidade de novos estudos. A utilização da nutrigenômica como ferramenta para criar dietas personalizadas deve considerar a diversidade de metabolismos e de necessidades decorrentes de diferentes modulações genéticas e atividades diárias das pessoas (52). Assim, utiliza-se da influência das características genéticas em uma nova forma de fazer recomendações nutricionais individualizadas, com a promoção principal da saúde e da escolha de alimentos específicos que auxiliem na redução das ocorrências de doenças crônicas não transmissíveis (53, 54). Por sua vez, existe o risco do reducionismo em conduzir a uma relação instrumental com o alimento a ponto de lhe atribuir um valor secundário, quando comparado com a saúde (55). O sucesso da nutrigenômica está condicionado à integração da ciência com a tradição cultural, emocional, ética 
e sensual da relação com o alimento. Deve-se considerar que o alimento é a base da formação, manutenção e evolução das sociedades, visto que o momento da ingestão materializa um dos raros instantes da vida em que o sujeito abre totalmente seu organismo para incorporar o mundo exterior. Logo, automaticamente, está vulnerável a incorporar elementos físicos e emocionais que podem ser nocivos (55). Nordström, Jönsson, Nordenfelt e Görman (55) reforçaram que o alimento representa o empoderamento biopsicossocial, representando um ato deliberado na construção da identidade pessoal.

A exacerbação da suplementação nutricional pode reduzir o ato da alimentação apenas à ingestão de nutrientes básicos e descontextualizar o processo biológico, fisiológico e social (56). Dessa forma, recomendou-se que a dieta personalizada não devesse apenas ajustar a alimentação, mas também o estilo de vida (54). Mudanças de hábitos são difíceis, principalmente se abrangerem a alimentação, devido às representações envolvidas no processo de produção, preparo e consumo, cujo autoconhecimento, criticidade e protagonismo são importantes para alcançar a qualidade de vida. Nesse contexto, para Hurlimann ET AL. (56), devido ao papel sociocultural do alimento, a recomendação dietética pode ser recebida com resistência por ser percebida como um obstáculo para as tradições culturais, para as conexões entre os membros da família e para a percepção holística de saúde, apresentando distintas expressões que dependem de fatores geográficos, étnicos e socioeconômicos. Os autores alertaram para a preocupação das pessoas em transformarem alimento em medicação e passarem a perceber o alimento in natura como algo perigoso.

\section{Nutrigenômica sob a perspectiva da saúde}

O principal benefício atrelado à nutrigenômica é a possibilidade de prevenir o aparecimento de doenças e diminuir a vulnerabilidade dos doentes, o que aliviaria as demandas da saúde pública. A relação das pessoas com a saúde tem influências pessoais e sociais que devem ser inseridas na discussão de como implementar a nutrição personalizada. A saúde pode ser percebida no meio médico simplesmente como viés estatístico, cuja doença é entendida como a ausência daquela; por consequência, o foco da intervenção médica parte da doença para sua mitigação. Além disso, pode ser analisada com base em uma visão holística, na qual o indivíduo saudável é entendido a partir da sua habilidade em associar metas vitais, preferências e saúde, entendendo a saúde como qualidade de vida (55). Para Nordström, Jönsson, Nordenfelt e Görman (55), a nutrigenômica deve adotar a visão holística, na qual a motivação para promover a saúde é individual, munida pelo autoconhecimento e pelo interesse no autocuidado. Para tal, o profissional de saúde deve elaborar estratégias de informação, sensibilização e conscientização para cada paciente.

A exagerada atenção e valorização da saúde pelas sociedades ocidentais foi vista como uma questão preocupante (57). Embora essas sociedades tenham dobrado a expetativa de vida nas últimas décadas, a obsessão pela saúde, principalmente por parte da classe média, pode ser reflexo de uma redução da autonomia na escolha. Isso porque se encontra diante da concepção do alimento como medicamento e da diminuição da percepção da saúde como um limitante do bem-estar geral. Profissionais da saúde canadenses consideraram que a associação da saúde com o estilo de vida independe de testes genéticos mais precisos, sendo a conduta preventiva almejada pelos profissionais e pela sociedade atual detentora de maiores níveis de informação, educação e monetário (58).

As síndromes metabólicas decorrentes do mau funcionamento do organismo, desencadeado por múltiplos fatores genéticos, como a consanguinidade, e ambientais, tais como alimentação e estresse, são atualmente generalizadas, o que se torna uma preocupação da saúde pública (16). Entre os agravos à saúde e as principais causas de morte no Brasil, Brant ET AL. (59) destacaram que as doenças crônicas não transmissíveis são as mais violentas e notadamente evitáveis. A intervenção pode se dar por meio da mudança de modo de vida, de dietas e do consumo de alimentos funcionais, suplementos e nutracêuticos, 
cuja eficácia pode ser maior, caso a intervenção seja adaptada ao indivíduo mediante marcas genéticas $(14,15)$. A expectativa da adesão popular por tratamentos nutrigenômicos e consequente prevenção de doenças faz com que essa área seja de interesse da saúde pública, principalmente no que tange à possível redução de custos, uma vez que há redução dos efeitos colaterais associados à medicação generalizada (14). A dieta personalizada pode auxiliar em resultados mais satisfatórios para a saúde, contanto que leve em conta a herança genética (que pode ter alterações decorrentes da influência da condição de saúde física e dos hábitos dos progenitores) e o estilo de vida do paciente.

\section{Nutrigenômica sob a perspectiva legal}

Além dos resultados do presente estudo atestarem para a necessidade da consolidação de uma base filosófica, teórica e ética para alicerçar a controversa aplicação da nutrigenômica, concomitantemente, deve-se prover proteção legal. Todo cidadão tem seu direito resguardado no que tange a meios e instrumentalização para que possa exercer o autocuidado com autonomia e ter acesso à informação, a mbiente e alimentação saudáveis. Promover autonomia dos sujeitos no seu modo de viver por meio de informações que favoreçam as suas escolhas responsáveis e saudáveis poderá garantir-lhes maior qualidade de vida e saúde (17). Contudo, ser autônomo não é a mesma coisa que ser respeitado como um agente autônomo (60). Logo, devido à íntima relação com a vulnerabilidade diante desse conflito, o cidadão deve ter garantido o direito de autodeterminação, que sustenta o direito de autonomia, confidencialidade e privacidade. Nos termos da Resolução 466/2012 do Conselho Nacional de Saúde do Brasil, a vulnerabilidade refere-se ao estado de pessoas ou grupos que, por diferentes motivos, tenham a sua capacidade de autodeterminação reduzida ou impedida, ou, de qualquer forma, estejam impedidos de opor resistência, sobretudo no que se refere aos termos da pesquisa (61).

O excesso de normas alimenta a burocracia, e esta infla os custos da pesquisa, podendo dificultar e até inviabilizar o processo. Acordos internacionais já sinalizam a mobilização da gestão pública para prevenir doenças por meio da manutenção do ambiente saudável. A Declaração Universal dos Direitos Humanos - dudh - (62), os objetivos de desenvolvimento sustentável e a apa são documentos que devem ser inseridos na questão da nutrigenômica. A dudh garante a alimentação adequada como condição primária para o exercício da cidadania. A alimentação adequada é um direito inerente a todas as pessoas quanto ao acesso regular, permanente e irrestrito, quer diretamente, quer por meio de aquisições financeiras, a alimentos seguros e saudáveis em quantidade e qualidade adequadas e suficientes. Assim, a alimentação adequada é um dos direitos fundamentais previstos no ordenamento jurídico nacional e internacional (dudh, 61), no Pacto Internacional de Direitos Humanos, Econômicos, Sociais e Culturais de 1966 (63) e na Convenção sobre os Direitos da Criança (64). A estratégia da apa é fortalecer comunidades locais balizadas em princípios de sustentabilidade, equidade, cooperação, comunicação e responsabilidade, o que lhe dá um caráter interdisciplinar. Ao promover um novo modelo de gestão ambiental, inclui a participação ativa de todos os atores em prol da organização, da prevenção, da proteção, da diversidade, da autogestão, da autonomia e da solidariedade (65).

Existe a necessidade da criação de novas legislações para a inserção da nutrigenômica ou a adequação das já existentes, sendo imprescindível que incorporem a percepção da população e considerem que o pouco tempo de atuação da nutrigenômica é insuficiente para determinar quais são as boas práticas esperadas (20). Bergmann, Görman, Mathers (57) e Bergmann, Bodzioch, Bonet, Defoort, Lietz e Mathers (66) divulgaram parte das diretrizes na pesquisa nutrigenômica por meio de uma ferramenta implementada em 2004, denominada "European Nutrigenomics Organization" (nugo), em quatro áreas: a) proteção do participante da pesquisa por meio de informação e consentimento; b) geração e uso de informação genotípica; c) estabelecimento e manutenção de biobancos; d) troca de amostras e de dados. Os autores esperam que essas diretrizes ultrapassem a aplicação 
ética acadêmica e sejam incorporadas por comitês normalizadores, revistas científicas, agências de fomento e indústria.

\section{Identificação das vulnerabilidades na nutrigenômica por meio da perspectiva bioética}

A Bioética, como ferramenta para mitigar vulnerabilidades decorrentes do desenvolvimento da tecnologia, prevê a identificação dos argumentos e valores dos agentes morais. A nutrigenômica desafia a ética tradicional ao prover, por meio da geração de informação genética, a incerteza dos benefícios da área para a saúde e a ausência de ganhos imediatos para os participantes da pesquisa. A Bioética atua em duas frentes na mitigação de vulnerabilidades: a proteção dos participantes da pesquisa e a proteção dos interesses da sociedade $(46,57)$.

O participante da pesquisa em nutrigenômica, considerado como pilar do conhecimento almejado, está em posição de vulnerabilidade diante da restrição de informações e orientações. As restrições são justificadas pelos cientistas fundamentadas na integridade e na propriedade intelectual inerente à pesquisa de inovação. Os biobancos inserem uma nova dimensão ética ao incitar a insegurança de como serão armazenados e processados os dados disponíveis, e ao questionar se seria moral limitar o uso de informações genéticas pessoais e estagnar o conhecimento da manifestação de uma determinada enfermidade. Para que essa compreensão atinja os níveis desejados pela ciência, os biobancos deverão prever um processo de troca de informações em escala global, o que demandará normas internacionais. A aplicação dos resultados desta pesquisa também consta nas pautas de discussão da ética na nutrigenômica. Como exemplo, tem-se o dopping genético no esporte e a discriminação de grupos genéticos (67). Porém, para os autores, parar as pesquisas no momento atual é inviável; por sua vez, continuar sem uma legislação que coíba as práticas ilegais poderá ser catastrófico. Na perspectiva de uma Bioética principialista, segundo Schramm, Palácios e Rego
(68), quando se aplica esse modelo em diferentes sistemas sociais, em que parte dos atores sociais não apresenta as capacidades necessárias para se empoderar de uma qualidade de vida satisfatória, mostram-se a insuficiência e imparcialidade do fato. Segundo os autores, ao considerarmos que, nas sociedades complexas contemporâneas, existem diferenciações funcionais excludentes, é possível gerar pluralidades de paradigmas morais em permanente conflito.

Os pesquisadores de nutrigenômica, embora detenham o papel de agente moral diante das decisões de como e para que conduzir suas pesquisas, muitas vezes se encontram em condição de vulnerabilidade diante de uma área de pesquisa que exige investimento financeiro, para o qual a associação com a indústria é legitimada e almejada. A percepção dos pesquisadores foi estudada por Hurlimann ET AL. (56), que alertaram a discrepância entre o otimismo na efetividade da nutrigenômica e a postura cética diante dos riscos de as pessoas reconfigurarem alimento como medicamento, relacionarem alimento com risco, perderem autonomia de suas escolhas alimentares, sentirem-se pressionadas à realização de testes e serem discriminadas ou estigmatizadas por causa do seu perfil genético. Os autores ressaltaram que os fatores de risco devem ser igualmente considerados por pesquisadores, profissionais da saúde e legisladores.

Caulfield (21) considerou que as questões éticas, legais e sociais atreladas à nutrigenômica estão relacionadas com as patentes e com o comércio. Para o autor, a aproximação entre a indústria e a academia trouxe benefícios como patrocínio, disseminação e aplicação da tecnologia. Em contapartida, levantou questionamentos quanto ao direcionamento das pesquisas movidas pelo interesse do mercado. O incentivo para a geração de patentes é uma realidade na maioria dos centros de pesquisa que investem em inovação, porém argumentos contrários indicam que essa abordagem é prejudicial para a pesquisa. Isso porque, além de torná-la mais cara e complexa, já que demanda tempo do pesquisador para questões burocráticas, produz vulnerabilidades na realidade da nutrigenômica, 
uma vez que envolve diretamente acessibilidade à saúde. O pronunciamento da indústria em oferecer produtos e serviços para um público receptivo a essas inovações foi prematuro, pois necessita mais pesquisa, capacitação técnica e normatização (21).

A manipulação genética de vegetais e animais com vistas à incorporação de vitaminas e minerais na produção de nutracêuticos foi pontuada por Ferguson, Shelling, Lauren, Heyes, McNabb e Zealand (69) como um potencial risco e gerador de vulnerabilidades ambientais. Para Sutton (28), a intenção de produzir alimentos para genótipos individuais deve levar em conta os aspectos científicos e técnicos, os consumidores, o mercado e a ética. Mayer (70) defendeu o cultivo do transgênico, em especial o arroz dourado com o intuito de minimizar a deficiência de vitamina a. Para o autor, a fortificação dos alimentos é mais democrática do que a suplementação, principalmente em países pobres e rurais. Assim, ele considerou os cultivos biofortificados como uma prática sustentável, cuja associação entre a biotecnologia verde, a compreensão das rotas metabólicas e a biossíntese dos nutrientes se constitui de uma expectativa real de suprir a deficiência de outros micronutrientes essenciais, como ferro, zinco, vitamina e e aminoácidos. Bergmann, Görman, Mathers (57) levantaram a questão ética da apropriação da tecnologia pelo mercado, inquerindo o momento em que a evidência é suficiente para justificar a criação de um produto especial. Os autores alertaram que é necessário considerar se esse produto atingirá o grupo correto, se poderá causar insensibilização dos demais grupos para a necessidade de cuidar da saúde ou se poderá incentivar a obsessão por esta.

A vulnerabilidade do usuário da nutrigenômica permeia os interesses científicos e econômicos, vendo-se impotente diante da deficiência de informações e da instrumentalização cognitiva para lidar com o conteúdo disponível, contrário ao previsto na Declaração Universal sobre Bioética e Direitos Humanos (46). Stewart-Knox ET AL. (15) realizaram um levantamento com quase 65 mil pessoas originárias de seis países europeus, além de uma ampla revisão de literatura, em que atestaram que a alta adesão aos testes genéticos se relacionam principalmente com a preexistência de agravos de saúde próprios ou em seus familiares. $\mathrm{Na}$ amostra dos autores, apenas $27 \%$ se manifestaram motivados a se submeterem a uma dieta personalizada, sendo o participante da pesquisa do gênero masculino e destituído de doenças prévias o que se posicionou menos favorável. É importante se atentar para as diferenças culturais, uma vez que o público norte-americano se mostrou mais preocupado com o armazenamento e uso dos seus dados genéticos, enquanto os europeus se preocupavam mais com as consequências dos organismos geneticamente modificados (57). Para Nordström, Jönsson, Nordenfelt e Görman (55), não se deve reduzir o alimento à perspectiva biológica ou cultural, pois, como elemento vital, demanda diretrizes éticas que ultrapassem o oferecimento de informações de quais nutrientes devem ser consumidos ou rejeitados. Logo, deve-se desenvolver tecnologia de informação adequada para atender as expectativas de cada grupo. Lafrenière, Hurlimann, Menuz e Godard (71) avaliaram o perfil da população a partir de uma ferramenta de comunicação apoiada por arte visual. Embora os autores não tenham evidenciado efetividade no aumento do conhecimento, acreditam que a ferramenta promove a reflexão sobre a temática.

A aceitação pública dos benefícios prometidos pela nutrigenômica foi prontamente incorporada pelo mercado, que prematuramente se posicionou no segmento de oferecimento de produtos e serviços, porém sem o acompanhamento da legislação (20). Os testes genéticos estão disponíveis, contudo a incipiência de profissionais capacitados na interpretação e comunicação dos resultados e na orientação nutricional deixa o consumidor vulnerável a deduções errôneas e à precipitação no consumo de testes irreais e falsos suplementos $(20,56)$. Dessa forma, o Conselho Regional de Nutricionistas do Brasil (3a Região) indica que os profissionais que pretendem atuar nessa área se capacitem para interpretar corretamente os resultados (72). Além disso, o crescimento da procura por esses serviços pode criar uma frustração no consumidor, caso a legislação passe a impedir o funcionamento dessas empresas (20). Weir, Morin, Ries e Castle (58) pontuaram que, embora a sociedade seja receptiva aos testes e às consultas disponibilizadas pela internet, 
é fundamental que esse procedimento seja realizado em clínicas que possam prover toda a assistência ao paciente.

A formação de grupos sociais que compartilham certos padrões genéticos para viabilizar a intervenção da nutrigenômica é tida como um dos principais conflitos éticos. Nesse cenário, gestantes, crianças, idosos, portadores de determinadas doenças ou grupos étnicos poderiam incluir recomendações generalizadas. Questiona-se, então, que se fazer parte desses grupos poderia criar discriminação e estigmatização (56), além de a possibilidade de susceptibilidade a determinadas doenças causar também ansiedade e estresse. Penders, Horstman, Saris e Vos (73) pontuaram que a personalização leva tanto à individualização quanto à categorização, potencializando o surgimento de questões éticas que devem compor uma agenda única. A individualização implica a categorização dos indivíduos, aproximando dos semelhantes; embora ele possa ser distinguido como único, não será tratado como único. Isso incorre na questão de como esses grupos serão formados e as consequências sociais dessa classificação. Enquanto algumas dessas categorias podem gerar estigmas e discriminação, outras podem ser usadas pela indústria para mover a favor do seu interesse. Bergmann, Görman, Mathers (57) alertaram que fatores sociais e econômicos podem ser condições mais importantes do que os genéticos na compreensão e mitigação individual de agravos, sendo muitas vezes o aconselhamento genético em nível de população mais efetivo. Exemplificando, sabe-se que existe uma maior incidência de intolerância a lactose em afro-americanos e em asiáticos, cuja orientação se abstém de testes genéticos.

\section{A intervenção da Bioética na conclamação da mudança de paradigmas}

A inserção da nutrigenômica na área da saúde conclama uma mudança de paradigmas de uma medicina pautada na epidemiologia e na fisiologia, para uma medicina apoiada na biologia molecular e na genética (74). A indústria alimentícia e a farmacêutica deverão passar por um processo de mudança de paradigma do mercado, transpassando do marketing em massa para a personalização em massa (12), respeitando os princípios fundamentais descritos na Declaração Universal sobre Bioética e Direitos Humanos (46).

Pacientes que recebem orientações personalizadas e inseridas em seus contextos emocionais e de expectativa de vida atestaram melhores resultados do que os submetidos aos procedimentos tradicionais (57). Contudo, é necessário tempo para ouvir o paciente. Bartlett, Antoun e Zgheib (75) afirmaram que, embora haja uma expectativa no uso da medicina personalizada associada à farmacogênomica, à vacinogenômica e à nanogenômica no atendimento primário em saúde, principalmente no que tange à minimização dos efeitos adversos das drogas, muitas barreiras éticas, legais e sociais devem ser transpostas. Os autores destacaram que, mesmo diante das inciativas de normatização, há a necessidade de pesquisas mais robustas, de capacitação técnica e ética dos profissionais da saúde, e da compreensão da influência dos fatores econômicos, culturais e pessoais na manifestação de agravos à saúde.

A aplicação da medicina personalizada associada à nutrigenômica demanda quebra de paradigmas dos profissionais da saúde, que devem ir mais além do diagnóstico e do tratamento pautado em protocolos para um olhar para o indivíduo. Para tal, fazem-se necessárias formação técnica e ética, bem como mudança na forma de atendimento nos serviços de saúde (75). Castle e Reis (20) evidenciaram aumento de interesse dos profissionais pela nova abordagem, o que pode ser tomado como incentivo para preparar equipes multidisciplinares no trabalho integrado entre profissionais da área médica, saúde pública e prestadores de serviço. Essa almejada interação deve ser pautada em uma comunicação eficiente direcionada para o aconselhamento genético efetivo. Os autores pontuaram que as informações de um teste genético são complexas e susceptíveis à má interpretação, tais como falso positivo/falso negativo, agravadas pela falta de preparação dos estudantes da área da saúde tanto para questões genéticas quanto nutricionais. Segundo Weir, Morin, Ries e Castle (58), 
já começaram a surgir iniciativas da elaboração de diretrizes para a formação desses profissionais com a determinação das competências e das habilidades fundamentais.

A medicina personalizada também demanda mudanças de paradigmas do cidadão, que deve exercer mais autonomia e responsabilidade de suas escolhas alimentares (56). Obviamente, devendo ser instrumentalizado e dotado de orientação e informações eficientes (17). O acesso ao alimento inclui a segurança alimentar, a qual considera a disponibilidade, a acessibilidade, o armazenamento e a aceitabilidade. Logo, é essencial entender melhor como essas dimensões afetam os alimentos e quais as relações entre ambiente-dieta-saúde, o que exige programas de promoção à saúde e de prevenção de doenças associadas à alimentação e à nutrição. Esses marcos estão na Constituição Federal (76), na Lei Orgânica da Saúde (77), na Lei Orgânica de Segurança Alimentar e Nutricional (78), além do Código de Defesa do Consumidor (79), todos do Brasil.

A personalização da indústria de alimento funcional necessita da mudança de paradigma do marketing, que deve levar em conta a estrutura demográfica e a estrutura social específica de cada região. Além disso, devem-se somar à pesquisa científica a evidência clínica, a adesão dos consumidores a alimentos naturais e a medicina alternativa. Para a existência de uma comunicação eficiente e sem conflito de interesses, é essencial a confluência com o poder público na regulamentação, na capacitação e na difusão de informações dos profissionais da saúde, bem como na parceira com a indústria na produção de nutracêuticos específicos (28).

Ao refletir sobre considerações bioéticas para a nutrigenômica, Bergmann, Görman, Mathers (57) finalizaram questionando: a) as abordagens eficientes para a harmonização e padronização legal internacional; b) como transformar os instrumentos regulatórios em promoção de integridade e em burocracia; c) como efetivar a comunicação usando recursos tecnológicos; d) como transformar as informações genéticas individuais em um contexto de saúde e cuidado. No caso da pesquisa, devem-se aplicar os mesmos princípios de investigações biomédicas como a autonomia, a beneficência, a não maleficência e a justiça. Para Zwart (48), a diminuição da vulnerabilidade do consumidor, diante da interferência da indústria alimentícia e do mercado globalizado, é dependente da dinstrumentalização deste, quanto ao desenvolvimento de novas condutas e proatividade nos debates sobre os rumos da nutrigenômica e seus direitos quanto ao acesso a alimentos seguros e eficazes. Korthals e Komduur (29) se posicionam cautelosamente com relação à nutrigenômica, pontuando que não se deve negligenciar as incertezas em prol de uma promissora expectativa de apropriação pela saúde pública. Para Meijboom (80), deve-se preponderar uma relação de confiança entre consumidor e indústria de alimento e farmacêutica, permeada por informações verdadeiras e transparentes dos processos de produção, cuja responsabilidade deve ser compartilhada entre cidadãos, pesquisadores, indústria e governo.

\section{Considerações finais}

O panorama da nutrigenômica até o momento assinala uma expectativa de mitigar a vulnerabilidade do ser humano às condições de vida impostas pelas sociedades contemporâneas, cujo ritmo de vida tem oferecido poucas chances de promoção da saúde biopsicossocial. A possibilidade de conhecer as necessidades específicas individuais e de poder prover os nutrientes que já não são viáveis de serem obtidos in natura pode se constituir de alternativas para pessoas que se encontram em situação de risco. Por sua vez, assim como outras ciências inovadoras, a nutrigenômica traz atrelada uma série de incertezas técnicas, sociais e éticas, que não devem ser negligenciadas em prol do idôneo objetivo de prevenção de doenças, pois são plausíveis de gerarem mais vulnerabilidades.

A promoção de um ambiente saudável, de alimentos eficazes e seguros, do autocuidado e da autogestão da saúde como medidas preventivas são as expectativas ideais para que o ser humano desfrute de uma existência saudável. Contudo, as demandas modernas, principalmente decorrentes das impactantes alterações ambientais e da atuação do sistema capitalista de consumo, criaram um conflito 
entre o biológico e o cultural, cuja alternativa tecnológica inseriu um elemento conflitante a mais. Essas novas questões podem ser difíceis de resolver com a utilização dos recursos legais, morais e éticos atuais, portanto requerem a intervenção da Bioética como ferramenta para intermediar o diálogo e a busca de soluções consensuais.

A Bioética, todavia, se vê inserida na questão como regulamentadora das investigações, com o objetivo de superar a vulnerabilidade do participante da pesquisa diante dos interesses da ciência ou da indústria, da pouca capacitação técnica e ética dos profissionais. Além disso, das informações incipientes, incompletas ou manipuladas, potencialmente capazes de comprometer a tomada de decisão autônoma e consciente quanto à participação na pesquisa, no âmbito direto das consequências biopsicossociais da intervenção na sua integridade e quanto ao destino do seu material genético $(57,66)$. A Bioética pode e deve ter uma atuação mais ampla e efetiva, questionando a concepção e relação do ser humano com a natureza, com incentivos ao autoconhecimento e à autopercepção como ser vivo componente de uma teia de inter-relações atemporais. Estas, cada vez mais, demandam a instrumentalização desse cidadão quanto à sua criticidade, autonomia e protagonismo, para que contribua para um planeta melhor para todas as gerações de seres vivos.

\section{Referências}

1. Fortes PAC, Ribeiro H. Saúde global em tempos de globalização. Saude soc. 2014; 23(2):366-75. Dor: https:// doi.org/10.1590/S0104-12902014000200002

2. Fischer ML, Cunha TR, Renke VE, Sganzerla A, Santos JZ. Da ética ambiental à bioética ambiental: antecedentes, trajetórias e perspectivas. Hist. cienc. Saúde-Manguinhos. 2017;24(2):391-409. DoI: https:// doi.org/10.1590/s0104-59702017000200005

3. Brasil. Lei 9.795, de 27 de abril de 1999. Dispõe sobre a educação ambiental, institui a Política Nacional de Educação Ambiental e dá outras providências. Diário Oficial da União, Brasília, 28 abr. 1999. [internet]. [consultada 30 maio 2020]. Disponível em: http:// www.planalto.gov.br/ccivil_03/leis/19795.htm

4. Buss PM. Comissão Nacional sobre Determinantes Sociais da Saúde (cndss). 2006. Disponível em: https://www.who.int/social_determinants/resources/ ppt_cndss_bz.pdf

5. Gomes AC. Vigilância entomológica. Informe Epidemiológico do SUS. 2002;11(2):79-90. DoI: https://doi. org/10.5123/S0104-16732002000200004

6. Augusto LGS. Saúde e vigilância ambiental: um tema em construção. Epidemiologia e Serviços de Saúde. 2003;12(4):177-87. DoI: https://doi.org/10.5123/S167949742003000400002

7. Silva VA, Loreto MDS. Atenção primária ambiental e saúde da família: a necessidade da intersetorialidade. Serviço Social \& Realidade. 2011;19(1):91-124.

8. Gouveia N. Saúde e meio ambiente nas cidades: os desafios da saúde ambiental. Saude soc. [internet] 1999 [consultada em 26 abril 2020];8(1):49-61. DoI: 10.1590/ S0104-12901999000100005

9. Faleiros Jr. RG, Borges PCC. A macrobiética e os direitos humanos: um caminho para o humanismo dialético. Revista de bioética e Direito. 2012;26:13-21. DoI: https://doi.org/10.4321/S1886-58872012000300003

10. Barreto M.L. Desigualdades em saúde: uma perspectiva global. Ciênc. saúde coletiva [Internet]. 2017 [consultada em 12 abril 2020];22(7):2097-108. DOI: 10.1590/1413-81232017227.02742017

11. Potter VR. Bioética: ponte para o futuro. São Paulo: Edições Loyola; 2016.

12. Ghosh D, Skinner MA, Laing WA. Pharmacogenomics and nutrigenomics: Synergies and differences. European journal of clinical nutrition. 2007;61(5):567-74. DoI: https://doi.org/10.1038/sj.ejcn.1602590

13. Fujii TMM, Medeiros R, Yamada R. Nutrigenômica e nutrigenética: importantes conceitos para a ciência da nutrição. Nutrire — SBAN, 2010;35(1):149-66.

14. Subbiah MTR. Application of nutrigenomics in skin health: Nutraceutical or cosmeceutical? The J Clin Aesthet Dermatol. 2010;3(11):44.

15. Stewart-Knox BJ, Bunting BP, Gilpin S, Parr HJ, Pinhão S, Strain JJ ET AL. Attitudes toward genetic testing and personalised nutrition in a representative sample of European consumers. Brit J Nutr. 2008;101(7):98289. DoI: https://doi.org/10.1017/S0007114508055657

16. Ouhtit, A. Nutrigenomics: From promise to practice. Sultan Qaboos Univ. Med. J.. 2014;14(1):e1. DOI: https://doi.org/10.12816/0003328

17. Rosaneli CF, Silva DAC, Ramos AG. Vulnerabilidade e autonomia nas escolhas alimentares. Em: Parizi R, Rosaneli CF, organizadores. Bioética e Saúde Pública. Curitiba: CRV; 2016. pp. 173-183. 
18. Camp KM, Trujillo E. Position of the Academy of Nutrition and Dietetics: Nutritional genomics. Journal of Academy of Nutrition and Dietetics. 2014;114(2):299312. DoI: https://doi.org/10.1016/j.jand.2013.12.001

19. Vasconcelos FAG. A ciência da nutrição em trânsito: da nutrição e dietética à nutrigenômica. Rev. Nutr., Campinas. 2010;23(6):935-45. DoI: https://doi.org/10.1590/ S1415-52732010000600001

20. Castle D, Ries NM. Ethical, legal and social issues in nutrigenomics: The challenges of regulating service delivery and building health professional capacity. Mutat Res-Fund Mol M. 2007;622(1):138-43. DoI: https://doi.org/10.1016/j.mrfmmm.2007.03.017

21. Caulfield T. Nutrigenomics patents and commercialization: Old wine in a new bottle? OmicsInt. J. Integr. Biol.. 2009;13(1):63-7. DoI: https://doi.org/10.1089/ omi.2008.0048

22. Bardin L. Análise de conteúdo. Ed. rev. e amp. São Paulo: Edições 70; 2011.

23. Santana-Santos L, Prosdocim F, Ortega JM. Essential amino acid usage and evolutionary nutrigenomics of eukaryotes - Insights into the differential usage of amino acids in protein domains and extra-domains. Genet Mol Res. 2008;7(3):839-52. DoI: https://doi. org/10.4238/vol7-3X-Meeting002

24. Fialho E, Moreno FS, Ong TP. Nutrição no pós-genoma: fundamentos e aplicações de ferramentas ômicas. Rev. Nutr. de Campinas. 2008;21(6):757-66. DOI: https://doi.org/10.1590/S1415-52732008000600014

25. Santos-Zago LF, Botelho AP, Oliveira AC. Os efeitos do ácido linoléico conjugado no metabolismo animal: avanço das pesquisas e perspectivas para o futuro. Rev. Nutr. de Campinas. 2008;21(2):195-221. DOI: https://doi.org/10.1590/S1415-52732008000200008

26. Sales NMR, Pelegrini PB, Goersch MC. Nutrigenomics: Definitions and advances of this new science. Nutr Metab. 2014. doi:10.1155/2014/202759

27. Bubela T, Taylor B. Nutrigenomics, mass media and commercialization pressures. Health Law Rev. 2008;16(3):41.

28. Sutton KH. Nutrigenomics new. Considerations for the successful development and launch of personalised nutrigenomic foods. Mutat res-fund $\mathrm{Mol} \mathrm{M}$. 2007;622(1):117-21. DOI: https://doi.org/10.1016/j.mrfmmm.2007.03.007

29. Korthals M, Komduur R. Uncertainties of nutrigenomics and their ethical meaning. J Agr Environ Ethic. 2010;23(5):435-54. Dor: https://doi.org/10.1007/ s10806-009-9223-0
30. Veiga APM. Suscetibilidade a diabetes mellitus em cães obesos [tese de doutorado em ciência animal]. Porto Alegre: Faculdade de Medicina Veterinária, Universidade Federal do Rio Grande do Sul; 2007.

31. Sousa RQ, Dreschler LEMG, Silva VCL, Holanda GML. Diabetes mellitus canina e felina. Trabalho de Conclusão de Curso (Graduação em Medicina Veterinária). Universidade Federal Rural de Pernambuco; 2009.

32. Mendes-Jr AF, Passos CB, Gáleas MAV, Secchin MC, Aptekmann KP. Prevalência e fatores de risco da obesidade felina em Alegre-ES, Brasil. Semina. Ciênc. Agrár. 2013; 34: 180-1805. DoI: https://doi.org/10.543 3/1679-0359.2013v34n4p1801

33. Silvério MF. Obesidade no gato doméstico: verificação dos factores de risco associados à obesidade felina num Centro Urbano [dissertação de mestrado em Medicina Veterinária]. Lisboa: Universidade Lusófona de $\mathrm{Hu}-$ manidades e Tecnologias; 2013.

34. Kienzle E, Bergler R. Human-animal relationship in owners of normal and overweight cats. J Nutr, Bethesda. 2006;136(7):1947S-950S. DoI: https://doi. org/10.1093/jn/136.7.1947S

35. Galvão ALB, Borges JC, Vieira MC, Ferreira GS, Léga E, Pinto ML. Hipertensão arterial na doença renal crônica em pequenos animais: revisão de literatura. Nucl Anim. 2010;2:9-20. DoI: https://doi.org/10.3738/ na.v2i1.361

36. Santos Jr MB. Hipertensão arterial sistêmica em felinos. Programa de Pós-Graduação em Ciência Animal, Universidade Federal de Goiás; 2013 [internet]. [consultada el 26 de abr. de 2020]. Disponível em: https:// ppgca.evz.ufg.br/up/67/o/2013_Marcelo_Borges_seminariolcorrig.pdf

37. Brown S, Atkins C, Bagley R, Carr A, Cowgill L, Davidson $\mathrm{M}$ ET AL. Guidelines for the identification, evaluation, and management of systemic hypertension in dogs and cats. J Vet Intern Med. 2008;21(3):542-58. DoI: https://doi.org/10.1111/j.1939-1676.2007.tb03005.x

38 Weis M. Hipersensibilidade alimentar em cães: revisão de literatura [monografia de especialização em Clínica Média de Pequenos Animais]. Porto Alegre: Universidade Federal Rural do Semi-Árido; 2011.

39. Harvey R, Hall E. Alergia/intolerância alimentar. Veterinary Focus, Descalvado, SP: Royal Canin. 2009;19(1):3641. DoI: https://doi.org/10.1055/s-0034-1381806

40. Medleau L, Hnilica KA. Reações de Hipersensibilidade. Em: Hnilica KA, organizador. Dermatologia de Pequenos Animais: Atlas Colorido e Guia Terapêutico. São Paulo: Roca; 2003. pp. 108-09. 
41. Farias MR. Dermatite Atópica Canina: da Fisiologia ao Tratamento. Revista Clínica Veterinária, São Paulo. 2007;69:48-62.

42. Vester BM, Swanson K. Interações entre nutrients e genes: aplicação à nutrição e saúde dos animais de companhia. Aspectos Clínicos da Genética Canina. Veterinary Focus, Descalvado, SP: Royal Canin. 2007;17(2):40-44. DOI: https://doi.org/10.1055/s-0034-1381769

43. Camilo M, Sakamoto MI, Gomes MOS. Nutrição de cães em diferentes fases da vida. Boletim Técnico da Universidade Camilo Castelo Branco, Departamento de Produção Animal. 2014 [internet]. [consultada em 26 abril 2020]. Disponível em: https://universidadebrasil.edu.br/portal/_biblioteca/ uploads/20190610152907.pdf

44. Grandjean D. Tudo que você deve saber sobre o papel dos nutrientes na saúde de cães e gatos. São Paulo: Royal Canin. 2006; 3.

45. Pibot P. Ponto de vista Royal Canin... Raça: um parâmetro fundamental em nutrição canina. Em: Pibot P, org.Aspectos Clínicos da Genética Canina. Veterinary Focus, Descalvado, SP: Royal Canin. 2007;17(2):40-4. DOI: https://doi.org/10.1055/s-0034-1381769

46. Garrafa V, Kottow M, Saada A. Declaração Universal sobre Bioética e Direitos Humanos [internet]. Bases conceituais da bioética: enfoque latino-americano; 2006 [internet]. [consultada em 26 abril 2020]. Disponível em: http://bvsms.saude.gov.br/bvs/publicacoes/ declaracao_univ_bioetica_dir_hum.pdf

47. Jonas H. O Princípio Responsabilidade - Ensaio de uma ética para a civilização tecnológica. Rio de Janeiro: Editora PUC-Rio; 2006.

48. Zwart H. Biotechnology and naturalness in the genomics era: Plotting a timetable for the biotechnology debate. J Agr Environ Ethic. 2009;22(6):505-29. DoI: https://doi.org/10.1007/s10806-009-9178-1

49. Carneiro HS. Comida e sociedade: significados sociais na história da alimentação. História: Questões \& Debates. 2005;42;71-80. doi: https://doi.org/10.5380/his. $\mathrm{v} 42 \mathrm{i} 0.4640$

50. Boff L. Comensalidade: passagem do animal ao humano [Blog LeonardoBoff.com]. 2012 [consultada em 26 abril 2020]. [internet]. [consultada em 30 maio 2020]. Disponível em: https://leonardoboff. org/2012/10/15/comensalidade-passagem-do-animal-ao-humano/

51. Oliveira WK. Comensalidade: diaconia como comer junto. Anais do Congresso Internacional da Faculdades EST. São Leopoldo, RS. 2014;2:1172-183. [internet]. [consultada em 30 maio 2020]. Disponível em: http:// anais.est.edu.br/index.php/congresso/article/view/386

52. Assunção AW, Artmann M, Aerestrup JR. Dieta e nutrição na era pós-genoma: Nutrigenômica. rebes (Pombal-pb, Brasil). 2014;4(2):13-20.

53. Conti A, Moreno FS, Ong TP. Nutrigenômica: revolução genômica na nutrição. Cienc. Cult. 2010;62(2):4-5.

54. Lima ARC. Nutrigenómica [dissertação de mestrado em Ciências Farmacêuticas]. Porto: Universidade Fernando Pessoa; 2014. [internet]. [consultda em 30 maio 2020]. Disponível em https://bdigital.ufp.pt/bitstream/10284/4430/1/PPG_21173.pdf

55. Nordström K, Coff C, Jönsson H, Nordenfelt L, Görman U. Food and health: Individual, cultural, or scientific matters? Genesnutr. 2013;8(4):357. DOI: https://doi.org/10.1007/s12263-013-0336-8

56. Hurlimann T, Menuz V, Graham J, Robitaille J, Vohl MC, Godard B. Risks of nutrigenomics and nutrigenetics? What the scientists say. Genes nutr. 2014;9(1):370. DoI: https://doi.org/10.1007/s12263-013-0370-6

57. Bergmann MM, Görman U, Mathers JC. Bioethical considerations for human nutrigenomics. Annu. Rev. Nutr. 2008;28:447-67. DoI: https://doi.org/10.1146/annurev.nutr.28.061807.155344

58. Weir M, Morin K, Ries N, Castle D. Canadian health care professionals' knowledge, attitudes and perceptions of nutritional genomics. Brit J Nutr. 2010;104(8):1112-119. DoI: https://doi.org/10.1017/S0007114510002035

59. Brant LCC, Nascimento BR, Passos VMA, Duncan BB, Bensenõr IJM, Malta DC ET AL. Variações e diferenciais da mortalidade por doença cardiovascular no Brasil e em seus estados, em 1990 e 2015: estimativas do Estudo Carga Global de Doença. Rev. bras. epidemiol.. 2017;20(Supl 1):116-28. DoI: https://doi. org/10.1590/1980-5497201700050010

60. Beauchamp TL, Childress JF. Princípios de ética biomédica. 4. ed. São Paulo: Loyola; 2002.

61. Brasil. Conselho Nacional de Saúde. Resolução 466, de 12 de dezembro de 2012 [internet]. 2012 [consultada em 26 abril 2020]. Disponível em: http://bvsms.saude. gov.br/bvs/saudelegis/cns/2013/res0466_12_12_2012. html

62. Organização das Nações Unidas. Declaração Universal dos Direitos Humanos [internet]. 1948 [consultada em 26 abril 2020]. Disponível em: de https://nacoesunidas.org/wp-content/uploads/2018/10/DUDH.pdf

63. Organização das Nações Unidas. Assembleia Geral das Nações Unidas. Pacto Internacional sobre Direitos Econômicos, Sociais e Culturais - Pidesc [internet]. Adotado pela Assembleia das Nações Unidas em 16 
de dezembro de 1966 e em vigor em 3 de janeiro de 1976 [consultada em 26 abril 2020]. Disponível em: http://www.unfpa.org.br/Arquivos/pacto_internacional.pdf

64. Organização das Nações Unidas. Assembleia Geral das Nações Unidas. Convenção das Nações Unidas sobre os Direitos da Criança [internet]. Adotada pela Assembleia Geral das Nações Unidas em 20 de novembro de 1989 e ratificada pelo Brasil em 24 de setembro de 1990 [consultada em 26 abril 2020]. Disponível em: https://www.unicef.org/brazil/convencao-sobre-os-direitos-da-crianca

65. Atenção Primária Ambiental-APA (opas/bra/ hep/001/99). Trad. Cláudia Aparecida Apulino Marques. Brasília: Gráfica e Editora Brasil; 1999.

66. Bergmann MM, Bodzioch M, Bonet ML, Defoort C, Lietz G, Mathers JC. Bioethics in human nutrigenomics research: European Nutrigenomics Organisation workshop report. Brit J Nutr. 2006;95(5):1024-1027. DoI: https://doi.org/10.1079/BJN20061758

67. Cieszczyk P, Maciejewska A, Sawczuk M. New threats of genetic research in sport. J Sport Exerc. 2010;5(3):32227. DoI: https://doi.org/10.4100/jhse.2010.53.02

68. Schramm FR, Palácios M, Rego S. O modelo bioético principialista para a análise da moralidade da pesquisa científica envolvendo seres humanos ainda é satisfatório?. Ciênc. Saúde coletiva [internet]. 2008 [consultada em 26 abril 2020];13(2):361-370. DoI: 10.1590/S141381232008000200011

69. Ferguson LR, Shelling AN, Lauren D, Heyes JA, McNabb WC, Zealand NN. Nutrigenomics and gut health. Mutat Res. 2007;622(1-2):1-6. Editorial. DOI: https://doi.org/10.1016/j.mrfmmm.2007.05.001

70. Mayer JE. Golden rice, golden crops, golden prospects. Rev Colomb Biotecnol. 2007;9(1):22-34.

71. Lafrenière D, Hurlimann T, Menuz V, Godard B. Evaluation of a cartoon-based knowledge dissemination intervention on scientific and ethical challenges raised by nutrigenomics/nutrigenetics research. Eval Program Plann. 2014;46:103-114. Dor: https://doi.org/10.1016/j.evalprogplan.2014.06.002

72. Conserlho Regional de Nutrição. Conselho Regional de Nutricionistas - 3a Região. Parecer Técnico 9/2015. Gênomica Nutricional: Testes de Nutrigenética [internet]. mar. de 2015 [consultada em 26 abril 2020]. Disponível em: https://nutritotal.com.br/pro/wp-content/uploads/sites/3/2015/10/442-CRN3_NUTRIGENETICA.pdf
73. Penders B, Horstman K, Saris WH, Vos R. From individuals to groups: A review of the meaning of "personalized" in nutrigenomics. Trends in Food Science \& Technology. 2007;18(6):333-38. DoI: https://doi.org/10.1016/j.tifs.2007.02.004

74. Pavlidis C, Patrinos G, Katsila T. Nutrigenomics: A controversy. Applied \& translational genomics. 2015;4:50-3. DoI: https://doi.org/10.1016/j.atg.2015.02.003

75. Bartlett G, Antoun J, Zgheib NK. Theranostics in primary care: Pharmacogenomics tests and beyond. Expert review of molecular diagnostics. 2012;12(8):841-55. DoI: https://doi.org/10.1586/erm.12.115

76. Brasil. Constituição da República Federativa do Brasil de 1988. Brasília, 5 de out. de 1988. [internet]. [consultada em 30 maio 2020]. Disponível em: http://www. planalto.gov.br/ccivil_03/constituicao/constituicao. htm

77. Brasil. Lei 8.080, de 19 de setembro de 1990. Dispõe sobre as condições para a promoção, proteção e recuperação da saúde, a organização e o funcionamento dos serviços correspondentes e dá outras providências. Publicado no Diário Oficial da União. Organização das Nações Unidas. [internet]. [consultada em 30 maio 2020]. Disponível em: http://www.planalto.gov.br/ccivil_03/leis/18080.htm

78. Brasil. Lei 11.346, de 15 de setembro de 2006. Cria o Sistema Nacional de Segurança Alimentar e Nutricional-Sisan com vistas em assegurar o direito humano à alimentação adequada e dá outras providências. Publicado no Diário Oficial da União. 18 de set. de 2006. [internet]. [consultaada em 30 maio 2020]. Disponível em: http://www.planalto.gov.br/ccivil_03/_Ato20042006/2006/Lei/L11346.htm

79. Brasil. Lei 8.078 , de 11 de setembro de 1990. Dispõe sobre a proteção do consumidor e dá outras providências. Publicado no Diário Oficial da União. 12 set. 1990. [internet]. [consultada em 30 maio 2020]. Disponível em: http://www.planalto.gov.br/ccivil_03/leis/ 18078.htm

80. Meijboom FL. Trust, food, and health. Questions of trust at the interface between food and health. J Agr Environ Ethic. 2007;20(3):231-45. Dor: https://doi.org/10.1007/s10806-007-9035-z 